\title{
Clinical Profile of Children with Developmental Coordination Disorder - a prospective study
}

\author{
Dinesh Saroj ${ }^{1}$, Mona Gajre ${ }^{2}$, Rashmi Yeradkar ${ }^{3}$, Avinash De Sousa ${ }^{4}$ \\ ${ }^{1}$ Consultant, Fellowship in Learning Disability and Neurodevelopment Paediatrics \\ ${ }^{2}$ Professor and Unit Head, Department of Paediatrics Lokmanya Tilak Municipal Medical College and \\ General Hospital, Sion, Mumbai \\ ${ }^{3}$ Professor, Department of Occupational Therapy, Lokmanya Tilak Municipal Medical College and \\ General Hospital Mumbai. \\ ${ }^{4}$ Research Associate, Department of Psychiatry, Lokmanya Tilak Municipal Medical College, Mumbai. \\ Corresponding author: Dinesh Saroj \\ Email-dnshsaroj@gmail.com
}

\begin{abstract}
Background: Children with Development coordination disorder (DCD) deserve special attention because of poor awareness, delayed identification of the condition, its deleterious outcome on school and daily life tasks and lack of studies in Indian literature. The objective of the study is to study the profile of DCD children between 8-15 years age attending the Pediatric Neurodevelopmental Centre in a tertiary care public hospital. Methodology: After IRB approval and with prior consent, children referred for poor scholastic performance $(n=330)$ were screened between December 2015 to March 2016 for ophthalmological and hearing evaluation. Those with average Intelligence (IQ>85) were administered DSM-5 diagnostic criteria for DCD and DCD-Q'07 questionnaire $(\mathrm{n}=298)$. Co-morbidities like ADHD, articulation disorders and socialemotional affection were screened. They were subjected to Handwriting Legibility scale (HLS)- a subtest of Woodcock Johnson Test of Achievement. Suspected DCD children $(n=63)$ were administered Bruininks Osteretsky test of Motor Proficiency - short form (BOTMP-sf) for definitive diagnosis. Twenty-two children were lost to follow up. The data was analyzed using Microsoft Excel 2010 and SPSS version 20. Chi Square test and proportions were used to find out statistical significance.

Results: Total 13 (31.7\%) children belonged to 8-10 years age and 28 (68.2\%) were aged10.1-15 yrs. M:F ratio was 6:1. They had poor academic profile. ADHD, overweight and obesity, dysfluency of speech, poor self-esteem, disorganization in daily activities and clumsiness were seen as co-morbidities.

Conclusion: Better understanding of the profile of these children will help in formulating a multidisciplinary approach to assessment and guide in early therapeutic intervention.
\end{abstract}

Keywords: DCD, BOTMP, motor co-ordination, motor disorders, screening.

(Paper received $-10^{\text {th }}$ October 2019, Peer review completed $-25^{\text {th }}$ November 2019)

(Accepted $-26^{\text {th }}$ November 2019)

\section{INTRODUCTION}

Developmental coordination disorder (DCD) is characterized by deficits in the acquisition and execution of coordinated motor skills and is manifested by clumsiness, slowness and inaccuracy of motor skills that interfere with ADL (activities of daily living) skills [1]. It adversely influences a child's academic domain and significantly impacts on psycho-social and vocational outcomes. These children are subject to ridicule, both on the playground and in the classroom, where motor difficulties compromise their scholastic performance [2]. DCD children deserve special attention because of poor awareness amongst medical practitioners, allied health professionals, educators and therapists, delayed identification of the condition and its deleterious outcome on school and daily life tasks. Also, there are not many studies on DCD in 
Indian literature. Hence the objective of this study was to provide insight into profile of these children and facilitate early intervention.

All four DSM-5 criteria have to be met to establish diagnosis of DCD [3]. (criterion A) A significant impairment in the acquisition and execution of coordinated motor skills substantially below that expected given a person's chronological age; (criterion B) these motor problems significantly interfere with academic achievement or ADL; (criterion C) Onset of symptoms is in the early developmental period; and (criterion D) the motor problems are not explainable by intellectual disability, visual impairment or any neurological condition affecting movement (e.g., cerebral palsy, muscular dystrophy, degenerative disorder). These children tend to have average intellectual capacities and despite of motor difficulties, they have no identifiable neurological and sensory issues. The aim of the present study was to determine the profile of children with DCD aged 8-15 years referred from schools for academic concerns to the Paediatric Neurodevelopmental Centre (PND) in a tertiary care public hospital.

\section{METHODOLOGY}

After IRB clearance and an informed consent from the parents, all children $(n=330)$ referred from school to the PND centre from December 2015 to March 2016 for academic concerns were screened for visual acuity and hearing concerns. After ascertaining the average intelligence quotient (IQ>85) by Kamath Binet test, these children $(n=298)$ were administered DSM-5 diagnostic criteria for DCD and screened with Developmental Coordination Disorder Questionnaire (DCD'Q-07) to get suspects for DCD ( $n=63$ ).

DCDQ'07 is a short, easy to use and low-cost parent-report identification tool used for screening children with motor impairments between 5- 15 years of age. It consists of 15 items. It involves comparing the child's performance with that of typically developing peers [4] and each item is scored on a five-point Likert scale. Individual item scores are summed to give a total score ranging from 15 to 75 (higher scores indicate better motor co-ordination), which then indicates if the score suggests the presence, risk or absence of DCD.[3] We considered an individual item score of 3 or less as significant while more than 3 was considered insignificant. This is unlike other studies wherein factor analysis is used for data interpretation [5].

A detailed history relating to development, academic, social- emotional concerns, sports and other physical activities was sought. A general examination along with anthropometry was conducted to calculate Body mass index (BMI) (as per WHO growth charts) and neurological examination was done with special emphasis on writing skills and soft neurological signs. These children were screened for co-morbidities like Attention Deficit Hyperactivity Disorder (ADHD), articulation disorders and social -emotional affection. They were also subjected to Handwriting Legibility scale (HLS)- a subtest of Woodcock Johnson test of Achievement [6]. This test is used for standardised evaluation of handwriting skills by matching the child's handwriting to the samples on the scale. Both, legibility and general appearance of the writing sample is taken into account. The samples in scale are arranged along a 100-point scale, in increments of 10 points ranging from artistic to illegible. The handwriting Elements Checklist was also used for analysis based on six elements that affect handwriting quality- slant, spacing, size, horizontal alignment, letter formation and line quality. The Writing Evaluation Scale uses an analytic scoring method [6]

These children were administered Bruininks Osteretsky test of Motor Proficiency - short form (BOTMP-sf) for definitive diagnosis. It is a 46-item test that assesses the motor functioning of children from 4.5 to 14.5 years of age using selected items from the full scale and takes only 30 minutes to complete, as opposed to 2 hours for the full version [7]. Assessed parameters include running speed and agility, balance, bilateral coordination, strength, upper-limb coordination and dexterity, and response speed. A standard score (ageadjusted) below 38 , which is at or below the 10th percentile rank, was required to classify a diagnosis for DCD. Out of 63 suspect DCD, twenty-two were lost to follow up.

\section{STATISTICAL ANALYSIS}

We analysed the data using Microsoft Excel 2010 and SPSS version 20. Chi Square test and proportions were used to find out statistical significance. 


\section{RESULTS}

Table 1: Demographic profile of children in our study population

\begin{tabular}{|l|l|l|l|l|l|l|}
\hline $\begin{array}{l}\text { Age } \\
\text { (years })\end{array}$ & $\begin{array}{l}\text { Male } \\
\text { N }(\%)\end{array}$ & $\begin{array}{l}\text { Female } \\
\text { N (\%) }\end{array}$ & $\begin{array}{l}\text { Written work } \\
\text { avoidance } \\
\text { N (\%) }\end{array}$ & $\begin{array}{l}\text { Grade } \\
\text { Promotion\# } \\
\text { N (\%) }\end{array}$ & $\begin{array}{l}\text { Poor Reading } \\
\text { Comprehension } \\
\text { N (\%) }\end{array}$ & $\begin{array}{l}\text { Poor } \\
\text { Writing } \\
\text { N (\%) }\end{array}$ \\
\hline $\begin{array}{l}\mathbf{8 - 1 0} \\
(\mathrm{n}=13)\end{array}$ & $12(92.3)$ & $1(7.6)$ & $9(69.2)$ & $11(84.6)$ & $7(53.8)$ & $7(53.8)$ \\
\hline $\begin{array}{l}\mathbf{1 0 . 1 - 1 5} \\
(\mathrm{n}=28)\end{array}$ & $23(82.1)$ & $5(17.8)$ & $19(67.8)$ & $16(57.1)$ & $19(67.8)$ & $18(64.2)$ \\
\hline Total & $35(85.36)$ & $6(14.63)$ & $28(68)$ & $27(65.85)$ & $26(63.41)$ & $25(60.97)$ \\
\hline p value & 0.391 & & 0.930 & 0.084 & 0.386 & $0.0412^{*}$ \\
\hline
\end{tabular}

*significant; \#(Grade promotion - promotion of grade according to Right To Education act).

Among 41 children diagnosed with DCD, 13 (31.7\%) children were 8-10 years age and 28 (68.2\%) were 10.1-15 years. $35(85.3 \%)$ were males and $6(14.6 \%)$ were females. M:F ratio was 6:1. $28(68 \%)$ showed tendency for written work avoidance. Academic history revealed $27(65.8 \%)$ were promoted to next class despite of poor academic grades. $26(63.4 \%)$ had poor reading comprehension while $61 \%$ displayed poor writing.

Table 2: Co-morbid disorders in our study population

All values in $\mathrm{N}(\%)$

\begin{tabular}{|c|c|c|c|c|}
\hline Age (years) & $\begin{array}{l}\text { 8-10 years } \\
(\mathrm{n}=13)\end{array}$ & $\begin{array}{l}\text { 10.1-15 years } \\
(\mathrm{n}=28)\end{array}$ & Total & p value \\
\hline ADD & $2(15.3)$ & $5(17.8)$ & $7(17.07)$ & \multirow[b]{2}{*}{0.992} \\
\hline ADHD-C & $8(61.5)$ & $19(67.8)$ & $27(65.85)$ & \\
\hline $\begin{array}{l}\text { Overweight } \\
\left(\text { BMI- } 25-29.9 \mathrm{~kg} / \mathrm{m}^{2}\right)\end{array}$ & $2(66.6)$ & $4(14.2)$ & $6(14.63)$ & \multirow[b]{2}{*}{$0.020^{*}$} \\
\hline $\begin{array}{l}\text { Obesity } \\
\left(\text { BMI- } 30-39.9 \mathrm{~kg} / \mathrm{m}^{2}\right)\end{array}$ & $1(7.6)$ & $9(32.1)$ & $10(24.40)$ & \\
\hline Dysfluency of speech & $4(30.7)$ & $6(21.4)$ & $10(24.40)$ & 0.517 \\
\hline Poor self esteem & $5(38.4)$ & $15(53.5)$ & $20(48.78)$ & 0.620 \\
\hline $\begin{array}{l}\text { Disorganised in daily } \\
\text { activities }\end{array}$ & $5(38.4)$ & $13(46.4)$ & $18(43.9)$ & 0.632 \\
\hline Clumsiness & $12(92.3)$ & $21(75.0)$ & $33(80.48)$ & $0.014^{*}$ \\
\hline
\end{tabular}

BMI- Body Mass Index, ADD- Attention Deficit Disorder, ADHD-C: Attention Deficit Hyperactivity

Disorder- combined

On analysing co-morbidities, 7(17\%) children ADD while 27(65.8\%) had ADHD-C. As per WHO growth charts for Body mass index, 6 (14.6\%) children were overweight while 10 (24.4\%) were obese. 10 (24.4\%) children had history of misarticulations of speech. 20 (48.7\%) had poor self-esteem. 18 (44\%) were disorganised in daily activities and 33 (80.4\%) were reported to be clumsy.

The daily activities were also impacted as $25(61 \%)$ had concerns with throwing a ball, 31 (75.6\%) had difficulty with writing speed and legibility and with craft activities. $15(36.5 \%)$ children showed poor interest in sports. Difficulty learning new motor tasks was seen with 25 (61\%) children. 24(60\%) children were incompetent with physical activity (Table 3 ). On HLS, $53.8 \%$ children in 8-10.1 yrs group and $35.7 \%$ in 11 15 yrs group scored below age equivalent, as is shown in Table 4. 
Table 3: Profile of DCD diagnosed children as per DCD'Q-07 questionnaire All values in $\mathrm{N}(\%)$

\begin{tabular}{|l|l|l|l|l|}
\hline Age (years) & $\begin{array}{l}\text { 8-10 years } \\
(\mathbf{n = 1 3 )}\end{array}$ & $\begin{array}{l}\mathbf{1 0 . 1 - 1 5} \text { years } \\
\mathbf{( n = 2 8 )}\end{array}$ & Total & $\mathbf{p}$ value \\
\hline $\begin{array}{l}\text { Concerns with throwing a } \\
\text { ball }\end{array}$ & $8(61.5)$ & $17(60.7)$ & $25(60.98)$ & 0.960 \\
\hline $\begin{array}{l}\text { Concerns with writing } \\
\text { speed and legibility }\end{array}$ & $9(69.2)$ & $22(78.5)$ & $31(75.6)$ & 0.517 \\
\hline $\begin{array}{l}\text { Concerns with craft } \\
\text { activities }\end{array}$ & $12(92.3)$ & $19(67.8)$ & $31(75.6)$ & 0.090 \\
\hline Interest in sports & $6(46.1)$ & $9(32.1)$ & $15(36.58)$ & 0.386 \\
\hline $\begin{array}{l}\text { Difficulties in learning } \\
\text { new motor tasks }\end{array}$ & $10(76.9)$ & $15(53.5)$ & $25(60.97)$ & 0.876 \\
\hline Physical competence & $6(46.1)$ & $11(39.2)$ & $17(41.46)$ & 0.431 \\
\hline
\end{tabular}

Table 4: Assessment of study population using the Handwriting legibility scale

\begin{tabular}{|c|c|c|c|}
\hline \multicolumn{5}{|c|}{ Overall Handwriting Legibility scores N (\%) } \\
\hline Age (years) & $\begin{array}{c}<\mathbf{4 0} \\
\text { AE }<8 \text { years }\end{array}$ & $\begin{array}{c}\mathbf{4 0 - 6 5} \\
\text { AE 8-16 years }\end{array}$ & $\begin{array}{c}>\mathbf{6 5} \\
\text { AE }>\mathbf{1 6} \text { years }\end{array}$ \\
\hline $\begin{array}{c}\mathbf{8}-\mathbf{1 0} \text { years } \\
(\mathbf{n}=\mathbf{1 3 )}\end{array}$ & $7(53.8)$ & $5(38.4)$ & $1(7.6)$ \\
\hline $\begin{array}{c}\mathbf{1 0 . 1 - 1 5} \text { years } \\
(\mathbf{n}=\mathbf{2 8})\end{array}$ & $10(35.7)$ & $14(50)$ & $4(14.2)$ \\
\hline $\begin{array}{c}\text { Total } \\
(\mathbf{n}=\mathbf{4 1})\end{array}$ & $17(41.46)$ & $19(46.34)$ & $5(12.19)$ \\
\hline $\mathbf{p}$ value & & 0.528 & \\
\hline
\end{tabular}

\section{DISCUSSION}

In routine primary care, paediatricians are rarely referred a child with primary motor coordination concerns. Often referrals are due to secondary impact on academics not explained by a specific learning disorder, socioemotional problems, bullying, obesity or poor self-esteem. The purpose of this study was to determine the profile of children with DCD and identify the comorbidities.

We had 41(12.4\%) children with diagnosed DCD. The prevalence of DCD in children aged 5-11 years is 5$6 \%$ [1]. We found that boys are affected more commonly as compared to girls with $\mathrm{M}: \mathrm{F}$ ratio being $6: 1$. In a study done earlier, boys were 1.7 to 2.8 times more likely than girls to have the disorder [8].

Difficulty with copying, drawing, painting, handwriting, organizing, and finishing work on time can adversely affect academic performance [9]. The resultant challenges and their repeated failures at schools adversely affect their self-esteem. As reported, these children are reluctant to participate in usual classroom activities, despite of studying in a regular classroom [10]. Likewise, in our study, these children exhibited a tendency towards avoidance of written work $(68 \%)$, had been promoted during their schooling years $(65.8$ $\%$ ), had poor reading comprehension (63.4\%) and displayed poor writing skills (60.9\%).

Almost 50\% children with DCD have co-morbid ADHD [11]. Together they predispose to severe combined type of ADHD and other neurodevelopmental and behavioural problems [12-13] and also predict further psychiatric illnesses. We found $83 \%$ children with co-morbid ADHD. This could be because of referral bias, ours being a tertiary care centre.

These children tend to refrain themselves from physical activities because of their self-perception of inadequacy to meet minimum performance expectations and competition posed by their contemporaries. 
Hence, they are prone for obesity and cardiovascular risks [14]. In our study, 6 (14.6\%) children were overweight while 10 (24.4\%) were obese.

The motor difficulties may also lead to significant secondary emotional and mental health concerns, e.g. low self-worth and self-esteem [13]. Similarly, we had 20(48.7 \%) children with poor self-esteem.18 (44\%) children were disorganised in daily activities and $33(80.4 \%)$ were clumsy. Poorer non-verbal communication skills predispose them for significant social problems, compared to their typically developing counterparts [15]. We had $10(24.4 \%)$ children with affected communication skills due to dysfluency of speech. As reported in 2004, the internal consistency of the DCDQ is high and the results from discriminant function analyses were appropriately strong for a screening tool. The overall sensitivity is $84.6 \%$ and the specificity is $70.8 \%$ [16]. For the age group $8-10$ years, sensitivity is $88.6 \%$ and specificity is $66.7 \%$ whereas for $10-15$ years age group, it is $88.5 \%$ and $75.6 \%$ respectively [16].

In a study conducted earlier, items on DCDQ like catching a ball, running and stopping, throwing a ball, jumping, ease in learning new motor skills, hitting a ball or birdie, planning an activity requiring motor coordination, and a tendency to avoid sports are the best predictors to differentiate non-DCD children from the diagnosed DCD and suspect DCD [7]. There is also marked slowness noticed in execution. Handwriting legibility and/or writing fluency gets affected with resultant deterioration in academic achievement [1].

The profile of these children on DCD'Q-07 questionnaire reflects concerns with throwing a ball (60.9\%), writing speed, legibility and craft activities $(75.6 \%)$, poor interest in sports $(36.5 \%)$, difficulty learning new motor tasks (61\%) and incompetency in physical activity (41.4\%) (table 3).

DCDQ'07 is most accurate in identifying children with DCD. However, further motor testing is required to establish the diagnosis [16]. The correlations between the DCDQ and BOTMP-sf are positive values, as high scores reflect better performance on both of these tests [7]. The short form does not give the details of each aspect of motor proficiency but it does provide an excellent assessment of general motor functioning [17]. The BOTMP long version is the gold standard for the diagnosis of DCD.

Written expression is an important parameter by which teachers evaluate the performance of their students. As effective writing requires the complex integration of many skills, children with DCD are likely to have difficulty with one or more aspects of the writing process, including handwriting, spelling, vocabulary, or expressing ideas. Accordingly, on standardised Handwriting legibility scale (HLS), 53.8 \% children of 8-10 years age scored below age equivalent and $35.7 \%$ in 10.1-15 years age group scored below 8 years of age.

\section{CONCLUSION}

Inadequacy of motor proficiency is associated with an increased risk for problems in other areas like academic, social and psychological. As a consequence, a multidisciplinary approach to assessment and intervention is required. It is highly significant to identify these children as early as possible with the help of appropriate measurement tools so as to initiate early intervention measures and provide accommodations so that they are successful in their life.

\section{REFERENCES}

1. Cermak SA, Larkin D. Developmental coordination disorder. Cengage Learning; 2002.

2. Zwicker JG, Missiuna C, Harris SR, Boyd LA. Developmental coordination disorder: a review and update. Eur J Paediatr Neurol 2012;16(6):573-81.

3. American Psychiatric Association. Diagnostic and statistical manual of mental disorders (DSM-5). American Psychiatric Pub; 2013.

4. Prado M, Magalhães LC, Wilson BN. Cross-cultural adaptation of the Developmental Coordination Disorder Questionnaire for Brazilian children. Brazil J Phys Ther 2009;13(3):236-43.

5. Rivard L, Missiuna C, McCauley D, Cairney J. Descriptive and factor analysis of the Developmental Coordination Disorder Questionnaire (DCDQ '07) in a population- based sample of children with and without Developmental Coordination Disorder. Child Care Health Dev 2014;40(1):42-9.

6. Mather N. An instructional guide to the Woodcock-Johnson Psycho-Educational Battery-Revised. Clinical Psychology Publishing Co; 1991.

7. Wilson BN, Kaplan BJ, Crawford SG, Campbell A, Dewey D. Reliability and validity of a parent questionnaire on childhood motor skills. Am J Occup Ther 2000;54(5):484-93. 
8. Faebo Larsen R, Hvas Mortensen L, Martinussen T, Nybo Andersen AM. Determinants of developmental coordination disorder in 7- year- old children: a study of children in the Danish National Birth Cohort. Dev Med Child Neurol 2013;55(11):1016-22.

9. Zwicker JG, Missiuna C, Harris SR, Boyd LA. Developmental coordination disorder: a review and update. Eur J Peadiatr Neurol 2012;16(6):573-81.

10. Mandich $\mathrm{AD}$, Polatajko HJ, Rodger S. Rites of passage: Understanding participation of children with developmental coordination disorder. Hum Movment Sci 2003;22(4-5):583-95.

11. Pitcher TM, Piek JP, Hay DA. Fine and gross motor ability in males with ADHD. Dev Med Child Neurol 2003;45(8):525-35.

12. Tervo RC, Azuma S, Fogas B, Fiechtner H. Children with ADHD and motor dysfunction compared with children with ADHD only. Dev Med Child Neurol 2002;44(6):383-90.

13. Zwicker JG, Harris SR, Klassen AF. Quality of life domains affected in children with developmental coordination disorder: a systematic review. Child Care Health Dev 2013;39(4):562-80.

14. Cairney J, Hay JA, Faught BE, Hawes R. Developmental coordination disorder and overweight and obesity in children aged 9-14 y. Int J Obesity 2005;29(4):369-72.

15. Dunford C, Missiuna C, Street E, Sibert J. Children's perceptions of the impact of developmental coordination disorder on activities of daily living. Br J Occup Ther 2005;68(5):207-14.

16. Wilson BN, Crawford SG, Green D, Roberts G, Aylott A, Kaplan BJ. Psychometric properties of the revised developmental coordination disorder questionnaire. Phys Occup Ther Pediatr 2009;29(2):182-202.

17. Flegel J, HA Kolobe T. Predictive validity of the Test of Infant Motor Performance as measured by the Bruininks-Oseretsky Test of Motor Proficiency at school age. Phys Ther 2002;82(8):762-71.

$* * * * * * * * * * * * * * * * * * * * * * * * * * * * * * * * * * * *$

Acknowledgements - Nil

Conflict of Interest - Nil

Funding - Nil 